\title{
Modified calcium oxide as stable solid base catalyst for Aldol condensation reaction
}

\author{
YING TANG*, JINGFANG XU and XUEFAN GU \\ College of Chemistry and Chemical Engineering, Xi' an Shiyou University, Xi' an Shaanxi, China \\ e-mail: tangying78@xsyu.edu.cn
}

MS received 19 February 2012; revised 15 May 2012; accepted 15 June 2012

\begin{abstract}
A highly efficient and stable solid-base catalyst for Aldol condensation was prepared by modifying commercial $\mathrm{CaO}$ with benzyl bromide in a simple way. It was found that modified $\mathrm{CaO}$ can effectively catalyse the Aldol condensation of cyclohexanone and benzaldehyde, as well as various benzaldehydes, to produce 2benzylidenecyclohexanone with a good selectivity and high yield. Higher yield of 95.8\% was obtained over modified $\mathrm{CaO}$ after $3 \mathrm{~h}$, which is short compared with the yield of $92.1 \%$ after $12 \mathrm{~h}$ over commercial $\mathrm{CaO}$. The influence of several reaction parameters, such as temperature, catalyst loading, was investigated. The humidity test over modified $\mathrm{CaO}$ reveals that the basic centres of modified $\mathrm{CaO}$ are stable for $\mathrm{CO}_{2}$ and moisture. From the results of Fourier transform-infrared (FT-IR) and Thermogravity analysis (TG) characterization, the modifier was bonded on surface of $\mathrm{CaO}$ chemically and almost no $\mathrm{Ca}(\mathrm{OH})_{2}$ formed during the modification process. The type of aldehyde has great influence on the yield of aldol condensation.
\end{abstract}

Keywords. Aldol condensation; $\mathrm{CaO}$; surface modification.

\section{Introduction}

Important role of Aldol condensation in the reaction involving $\mathrm{C}-\mathrm{C}$ bond formation makes it necessary for obtaining many fine chemicals of commercial interest. This kind of reaction can catalytically undergo in the presence of a strong base or acid in liquid phase. ${ }^{1-3}$ However, high operating costs and serious environmental issues associated with product separation, purification, corrosion and waste generation attract great efforts toward the development of processes mediated by heterogeneous catalysts. A recent topic of interest in the Aldol condensation is the use of solid base catalysts. Different families of solid bases have been found active in this reaction, including alkaliexchanged zeolites, ${ }^{4}$ ion-exchange resins, ${ }^{5,6}$ aluminasupported hydroxide, ${ }^{7,8} \mathrm{Mg}-\mathrm{Al}$ hydrotalcites ${ }^{9,10}$ and alkaline-earth metal oxides. ${ }^{11,12}$ In particular, alkalineearth metal oxides and hydrotalcite have been regarded as the most potential catalyst for industrial application for its strong basicity and low cost, especially for $\mathrm{CaO}$. However, this solid base has not broadly reached the industrial scene for the technical aspect about the stability of these catalysts upon exposure to moisture air. The basic sites of alkaline-earth metal oxides or hydrotalcite-like samples surface are easy to be

*For correspondence poisoned by air due to the adsorption of $\mathrm{CO}_{2}$ and $\mathrm{H}_{2} \mathrm{O}$ on the surface. ${ }^{13}$ Furthermore, the single contact between reagents and catalysts causes the catalyst less active than homogeneous strong base, such as sodium hydroxide. Many efforts have been taken towards the activity enhancement of such solid base catalysts by increasing their basicity. The published method for $\mathrm{Mg}-$ Al hydrotalcite activation is liquid-phase reconstruction to created surface base sites with uniformly distributed strength as suggested by Ebitani. ${ }^{14}$ It should be stressed that all operations during preparation, processing, storage and use of the catalyst was taken extremely carefully in inert gas atmosphere to avoid contacting with air.

Here, the aim of this study is to develop an activated $\mathrm{CaO}$ with high efficiency for the Aldol condensation of cyclohexanone and various benzaldehydes with good stability in moisture air. The modifying conditions and various reaction conditions were also investigated.

\section{Experimental}

\subsection{Modification of $\mathrm{CaO}$}

The surface modification procedure was as follows. Appropriate amount of commercial $\mathrm{CaO}$ particles (2.8 g, 100-160 mesh, China National Medicines Co., 


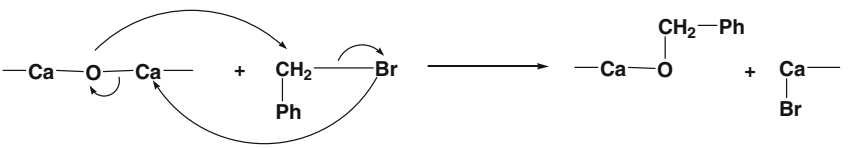

Scheme 1. The reaction between commercial $\mathrm{CaO}$ and benzyl bromide.

Ltd.) were added into the benzyl bromide (SigmaAldrich, AR)/methanol solution $(40 \mathrm{~mL})$ under stirring at room temperature for activation suggested as in scheme 1 . The content of benzyl bromide was varied from $0.01 \%$ to $0.5 \%$. After $24 \mathrm{~h}$, the mixture was separated and washed with methanol to remove excess modifier, and the modified $\mathrm{CaO}$ was obtained after a vacuum drying process. In order to increase the reproducibility, the particles were sieved before use. Particles of 100-160 mesh size were selected for all experiments.

\subsection{Humidity test}

Amount of commercial $\mathrm{CaO}$ and modified $\mathrm{CaO}$ particles were kept in a container under saturated humidity at room temperature for several days to allow the absorption of water on the surface. The samples were weighed at regular intervals of time. The absorbing moisture rate $(\%)$ of the samples was evaluated by the following equation, using the $\Delta \mathrm{m}$ as increase weight, as well as the $\mathrm{m}_{0}$ as the initial weight.

$$
w \%=\frac{56 \Delta m}{18 m_{0}} \times 100 \%
$$

\subsection{Aldol condensation activity test}

As shown in scheme 2, $0.6 \mathrm{mmol}$ cyclohexanone (99\%) and $0.5 \mathrm{mmol}$ purified benzaldehyde $(99.9 \%$ ) (molar ratio of benzaldehyde: cyclohexanone $=1.2: 1$ ) were added into $20 \mathrm{ml} \mathrm{MeOH}$ in a $50 \mathrm{ml}$ round bottom flask equipped with magnetic stirrer and condenser, and then about $0.25 \mathrm{mmol}$ catalysts was introduced in a constant temperature. The reaction mixture was heated at required reaction temperature ranging from 20 to $65^{\circ} \mathrm{C}$ at atmospheric pressure. After the completion of reaction, the liquid was cooled and filtrated from the mixture and analysed by gas chromatography using a flame ionization detector and HP-5 capillary column of $30 \mathrm{~m}$ length and $0.25 \mathrm{~mm}$ diameter, programmed oven temperature of $50-280^{\circ} \mathrm{C}$ and $\mathrm{N}_{2}(1.5 \mathrm{ml} / \mathrm{min})$ as a carrier gas. The conversion and selectivity were calculated by area normalization method on a carbon basis and the carbon balances are within $100 \pm 5 \%$ (scheme 2).

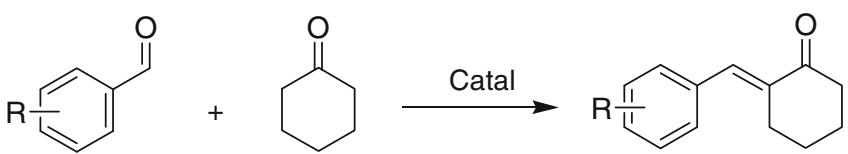

Scheme 2. Aldol condensations of cyclohexanone with benzaldehydes.

\subsection{Catalysts characterization}

The Fourier transform-infrared (FT-IR) spectrophotometer (Nicolet Nexus 670, USA) was used to identify the surface group over the catalyst. TGA experiments were carried out using Q600 SDT thermal analysis machine (TA Instruments, USA) under a flow of air in the temperature range from $25^{\circ} \mathrm{C}$ to $800^{\circ} \mathrm{C}$ with a ramping rate of $10^{\circ} \mathrm{C} \mathrm{min}^{-1}$.

\section{Results and discussion}

\subsection{Humidity test}

For $\mathrm{CaO}$, a water-absorptive material, the poisoning effect of $\mathrm{H}_{2} \mathrm{O}$ adsorption during catalyst preparation process are the most important problems to be resolved. The loading of modifier, benzyl bromide, are an important factors for the catalyst moisture absorption rate so to its catalytic activity for Aldol condensation. Too much modifier will lead the catalytic activity to decrease for the occupation of active sites on $\mathrm{CaO}$ surface, while fewer modifiers are insufficient for the formation of hydrophobic layer over catalyst surface. Furthermore, the resistance to moisture of the modified $\mathrm{CaO}$ will decrease due to a large amount of highly water-absorptive $\mathrm{CaBr}_{2}$ forms when too much benzyl bromide is used over $\mathrm{CaO}$ surface. Humidity tests were carried out over various modified $\mathrm{CaO}$ with modifier amount in the range from 0.01 to $0.5 \%$. For comparison, the unloaded sample was also included. The tested samples were kept in a vapour-saturated container at room temperature to allow the hydration and carbonation. The weight of each samples were measured at regular intervals of time, and the results were shown in figure 1. It was noted that the moisture absorption rate continues rising for all samples along with time. For the unmodified $\mathrm{CaO}$ particles, the moisture absorption rate increases rapidly and reaches to nearly $100 \%$ within $50 \mathrm{~h}$, while nearly no weight incensement can be found over modified $\mathrm{CaO}$ at the same time, and $0.2 \%$ benzyl bromide modified $\mathrm{CaO}$ gets the best moisture resistance. It is obvious that the surface modification can improve the moisture resistance of commercial $\mathrm{CaO}$ effectively. 


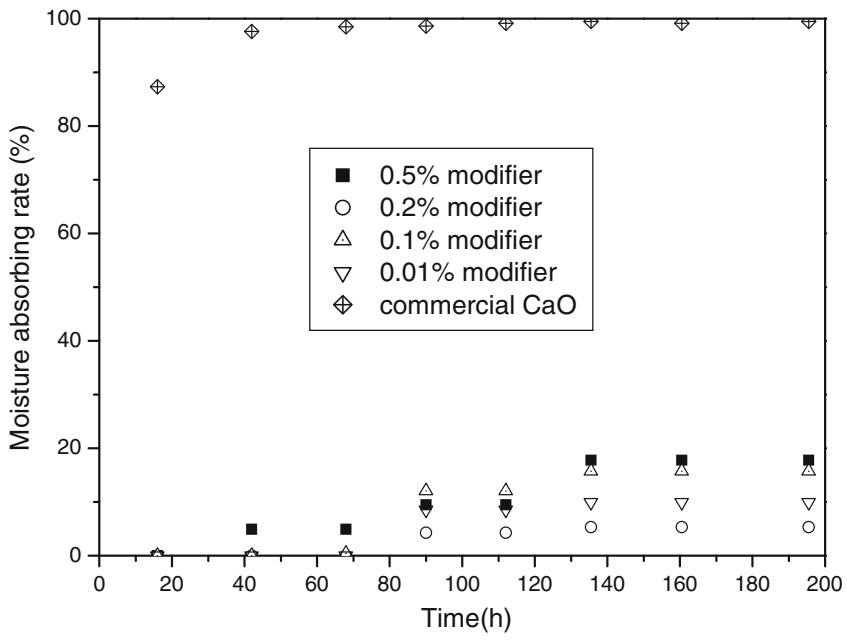

Figure 1. Moisture absorbing rate over commercial $\mathrm{CaO}$ and modified $\mathrm{CaO}$ with various benzyl bromides.

The figure 2 shows the FT-IR spectra of commercial $\mathrm{CaO}$ and modified $\mathrm{CaO}$. The spectra display bands at $867 \mathrm{~cm}^{-1}$ and $1477 \mathrm{~cm}^{-1}$ corresponding to vibration modes of mono and bidentate carbonates. It is also evidenced from the characteristic absorb of $\mathrm{C}=\mathrm{O}$ between 2000 and $1600 \mathrm{~cm}^{-1}$ that indicates the presence of calcium carbonate formed in both catalysts. However, there is no great difference between their intensity, suggesting carbonation by $\mathrm{CO}_{2}$ in air is very slight over modified $\mathrm{CaO}$. The bands at 1621 and $3460 \mathrm{~cm}^{-1}$ are associated with adsorbed water. The important features of the modified $\mathrm{CaO}$ appear in the $\mathrm{C}-\mathrm{H}$ (alkane) stretching (2800-3000 $\left.\mathrm{cm}^{-1}\right)$ and bending $\left(1440 \mathrm{~cm}^{-1}\right) .{ }^{15}$ The vibration of aromatic carbon double bond bands causes the incensement of intensity at 1600 and $1580 \mathrm{~cm}^{-1}$ and the aromatic carbon-hydrogen stretch $\left(3060 \mathrm{~cm}^{-1}\right)$ are

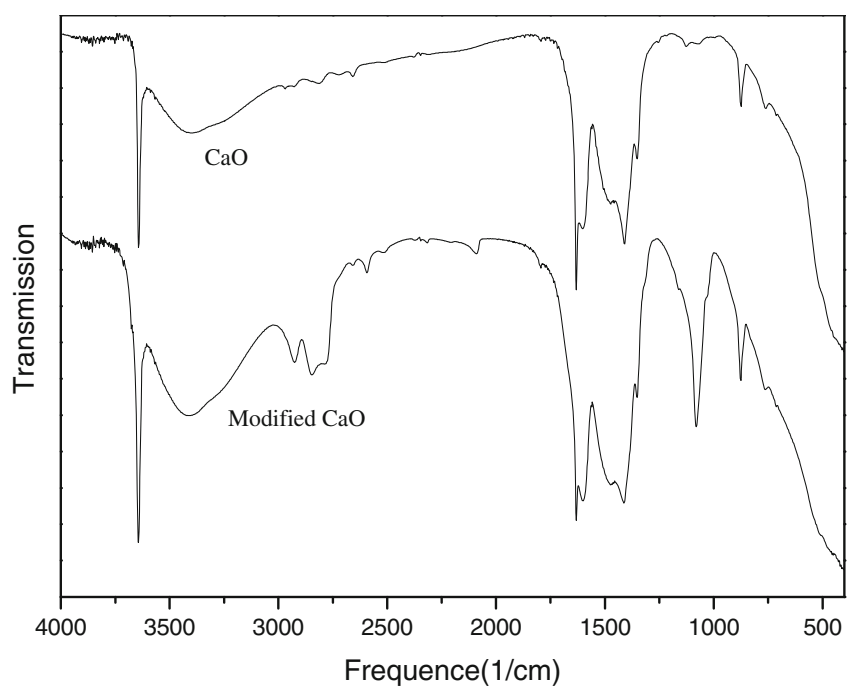

Figure 2. IR pattern of commercial $\mathrm{CaO}$ and modified $\mathrm{CaO}$.

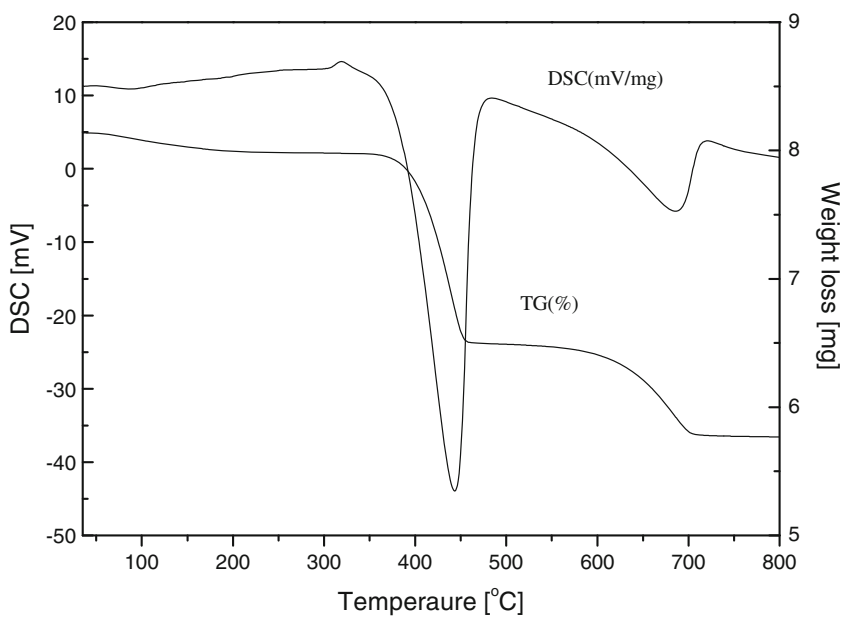

Figure 3. TG/DSC thermogram of modified $\mathrm{CaO}$.

evidence of the phenyl groups, which suggesting successful modification over commercial $\mathrm{CaO}$ surface. ${ }^{16}$

Figure 3 shows the TG/DSC thermogravity analysis of commercial $\mathrm{CaO}$ and modified $\mathrm{CaO}$. There are two steps in the $\mathrm{TG}$ curve in the temperature range from $400^{\circ} \mathrm{C}$ to $700^{\circ} \mathrm{C}$ due to the loss of $\mathrm{H}_{2} \mathrm{O}$ and $\mathrm{CO}_{2}$. Furthermore, the DSC curve of the modified $\mathrm{CaO}$ presents two broad peaks at $450^{\circ} \mathrm{C}$ and $700^{\circ} \mathrm{C}$ corresponding to the decomposition of $\mathrm{Ca}(\mathrm{OH})_{2}$ and $\mathrm{CaCO}_{3}$ formed by the hydration and carbonation of $\mathrm{CaO}$ in the storage and preparation. The peaks move to higher temperature range compared with commercial $\mathrm{CaO}\left(339^{\circ} \mathrm{C}\right.$ and $614^{\circ} \mathrm{C}$ ), which indicates the enhancement of thermal stability of modified $\mathrm{CaO}$. Furthermore, from the percentage of weight loss of the two samples, $2.305 \%$ for commercial $\mathrm{CaO}$ and $2.414 \%$ for modified $\mathrm{CaO}$, it can be concluded that the relatively little $\mathrm{Ca}(\mathrm{OH})_{2}$ forms during the modification procedure.

\subsection{Activity comparison of different catalysts}

Particularly, the Aldol condensation can be carried out on homogeneous basic catalysts with good yield and selectivity. A condensation of cyclohexanone and benzaldehyde was operated with kinds of bases at room temperature for $12 \mathrm{~h}$ with catalyst amount of $20 \mathrm{wt} \%$ as shown in figure 4 . From the results, it can be seen that among the homogeneous catalysts the reaction proceed increased with the basicity of catalyst with yield above $30 \%$, and the most efficient catalyst is $\mathrm{NaOH}$. Low catalytic activity for $\mathrm{Na}_{2} \mathrm{CO}_{3}$ was due to its weak basicity. Surprisingly, $\mathrm{CaO}$ showed highest activity of $83.6 \%$ yield of 2benzylidenecyclohexanone among the tested basic catalyst, indicating the basicity of $\mathrm{CaO}$ is strong and the most important factor to the active sites to improve the 


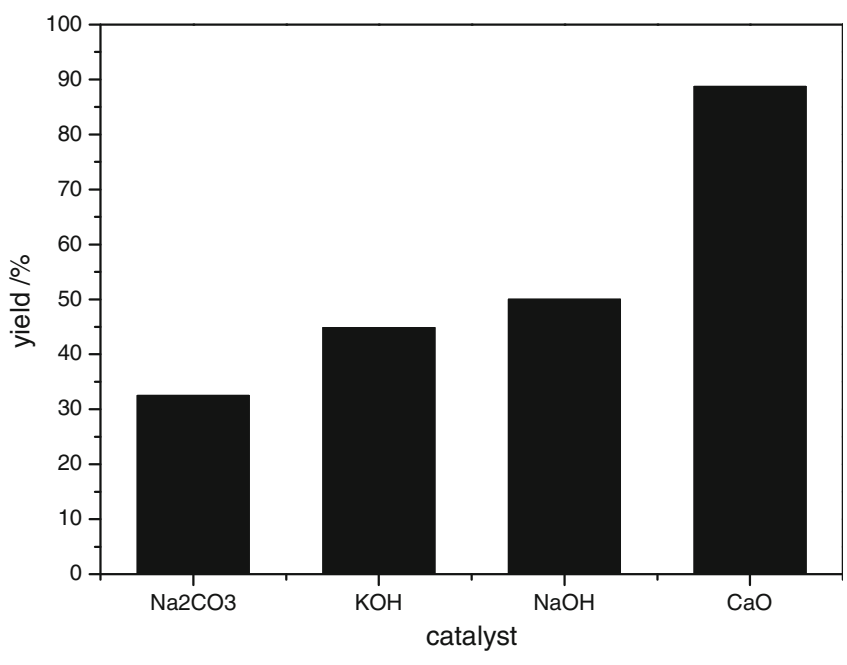

Figure 4. The catalytic performances of various catalysts in Aldol reaction of cyclohexanone and benzaldehyde (catalyst amount $=20 \%$, reaction time $=12 \mathrm{~h}$, cyclohexanone/ benzaldehyde $=1.2: 1$, reaction temperature $=65^{\circ} \mathrm{C}$ ).

abstraction of an $\alpha$-proton form the ketone molecule at the initial reaction and help the dehydration at the end of the reaction.

\subsection{Effect of catalyst amount}

The optimum amount of catalyst was investigated over commercial $\mathrm{CaO}$ with reaction time of $12 \mathrm{~h}$ at room temperature and cyclohexanone/benzaldehyde molar ratio of 1.2:1 (figure 5). The yield of 2benzylidenecyclohexanone increases along with the amount of catalyst. Lower $\mathrm{CaO}$ amount $(<2 \%)$, rela-

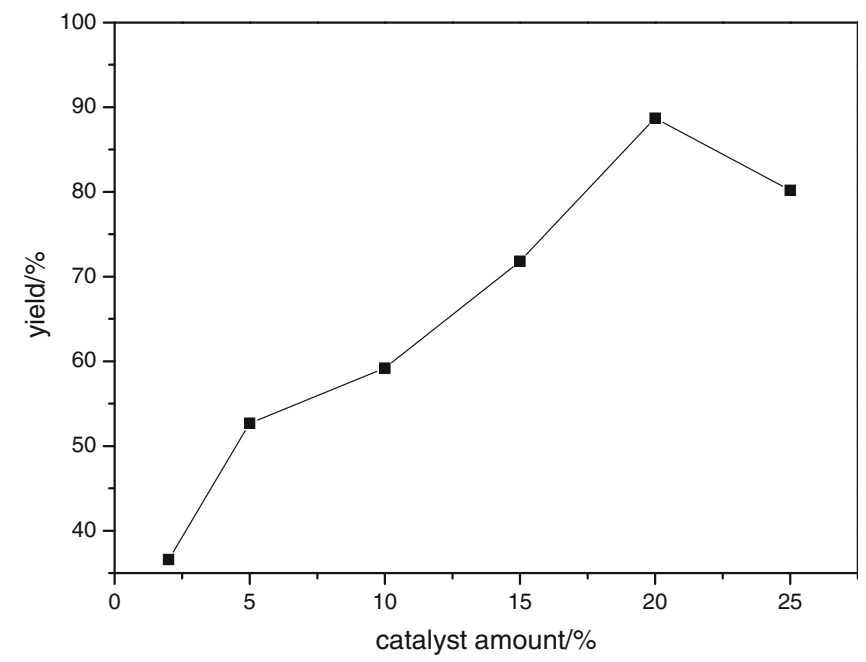

Figure 5. Effects of catalyst amount on Aldol condensation of cyclohexanone and benzaldehyde using commercial $\mathrm{CaO}$ as catalyst (reaction time $=12 \mathrm{~h}$, cyclohexanone/benzaldehyde $=1.2: 1$, reaction temperature $=65^{\circ} \mathrm{C}$ ). tively low yield $(36.6 \%)$ was observed. On increasing the catalyst amount to $20 \%$, the yield increased up to $94.5 \%$. However, too higher catalyst amount also leads to lower yield due to the decreased selectivity of 2-benzylidenecyclohexanone with the formation of 1,3,5-triphenylpentan-1,5-dione by Michael addition as suggested by Lopez. ${ }^{17}$

\subsection{Effect of reaction temperature}

The influence of the reaction temperature was investigated using a cyclohexanone/benzaldehyde molar ratio of $1.3: 1$ and $20 \mathrm{wt} \% \mathrm{CaO}$. Yield of 2benzylidenecyclohexanone was observed due to increase with reaction temperatures ranging from $20^{\circ} \mathrm{C}$ to $65^{\circ} \mathrm{C}$ as inferred from figure 6 . The results show that a yield of $90.1 \%$ at $20^{\circ} \mathrm{C}$ was obtained after $12 \mathrm{~h}$. With increase of the reaction temperature above $50^{\circ} \mathrm{C}$, the incensement of yield is not as high as the change in the low temperature range, which is similar to the results of Aldol condensation of citral and acetone reported by Raju et al. ${ }^{7}$ The optimum reaction temperature is $65^{\circ} \mathrm{C}$ for following experiments.

\subsection{Effect of cyclohexanone/benzaldehyde ratio}

To evaluate the effect of reagent concentrations on the yield of 2-benzylidenecyclohexanone, the reaction was carried out with the cyclohexanone/benzaldehyde ratio varied from 1.1 to 2.0. Figure 7 shows that the yield of 2-benzylidenecyclohexanone is the lowest with a cyclohexanone/benzaldehyde ratio of 1 :

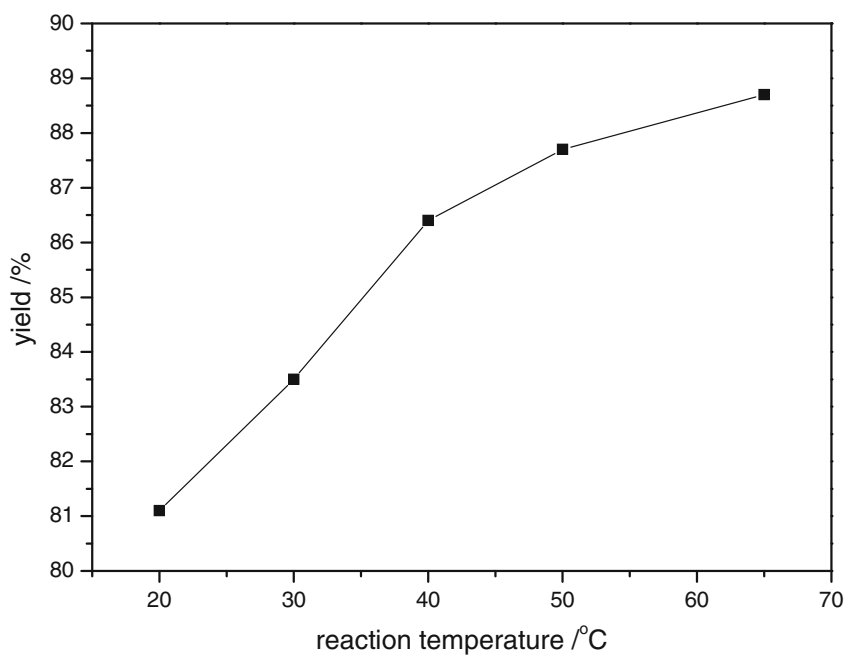

Figure 6. Effect of reaction temperature on Aldol condensation of cyclohexanone and benzaldehyde using commercial $\mathrm{CaO}$ as catalyst (catalyst amount $=20 \mathrm{wt} \%$, reaction time $=$ $12 \mathrm{~h}$, cyclohexanone/benzaldehyde $=1.2: 1$ ). 


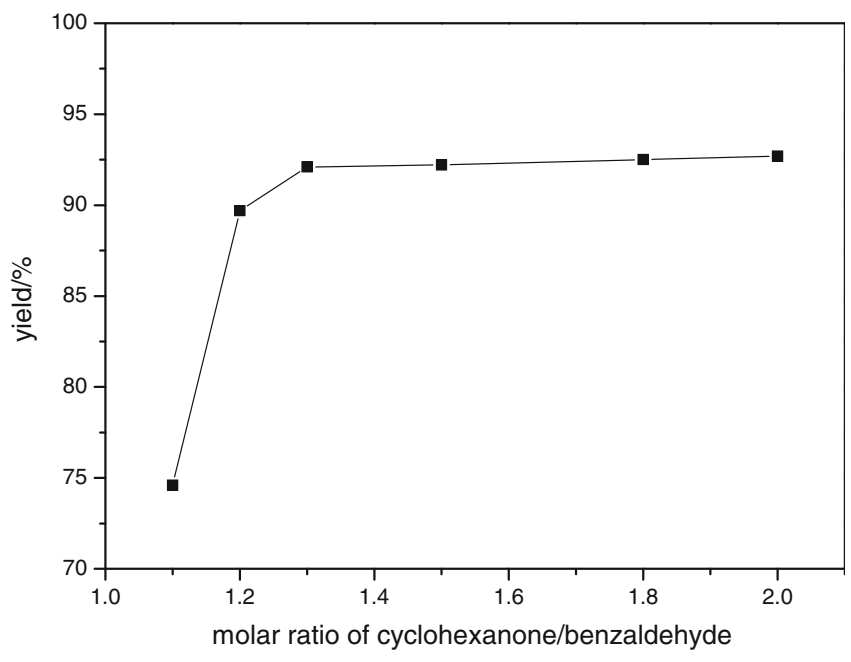

Figure 7. Effect of molar ratio on Aldol condensation of cyclohexanone and benzaldehyde using commercial $\mathrm{CaO}$ as catalyst (catalyst amount $=20 \mathrm{wt} \%$, reaction time $=12 \mathrm{~h}$, reaction temperature $=65^{\circ} \mathrm{C}$ ).

1.1. The yield enhances obviously as the cyclohexanone/benzaldehyde ratio increases. The highest yield was obtained with relatively low cyclohexanone/benzaldehyde ratio of $1: 1.3$ in comparison with reported high acetone/aldehyde ratio. ${ }^{1}$ The results show that commercial $\mathrm{CaO}$ is an effective catalyst for the Aldol condensation of cyclohexanone and benzaldehyde. Much higher cyclohexanone/benzaldehyde ratio has increased the yield slightly, so 1: 1.3 was chosen as the optimum cyclohexanone/benzaldehyde ratio.

\subsection{Effect of modifier loading}

The catalytic data over commercial $\mathrm{CaO}$ and modified $\mathrm{CaO}$ with different amount of benzyl bromide at the reaction temperature of $65^{\circ} \mathrm{C}$ with cyclohexanone/benzaldehyde molar ratio of $1: 1.3$ after $3 \mathrm{~h}$ were shown in figure 8 . From the results, it can be seen that the time to a high yield of 2-benzylidenecyclohexanone ( $>94 \%$ ) was greatly shorted from $12 \mathrm{~h}$ for commercial $\mathrm{CaO}$ to $3 \mathrm{~h}$ for modified $\mathrm{CaO}$. Furthermore, the catalytic activity of modified $\mathrm{CaO}$ increases along with the modifier's amount, and the highest activity $(94.7 \%$ yield of 2-benzylidenecyclohexanone) was obtained over $0.1 \%$ benzyl bromide modified $\mathrm{CaO}$. The high activity of modified $\mathrm{CaO}$ should be attributed to the phenyl groups forming a hydrophobic layer over $\mathrm{CaO}$ surface with similar structure to reactance, which greatly improve the diffusion of reactance to the catalyst surface and make the utilization of active sites over catalyst surface efficient.

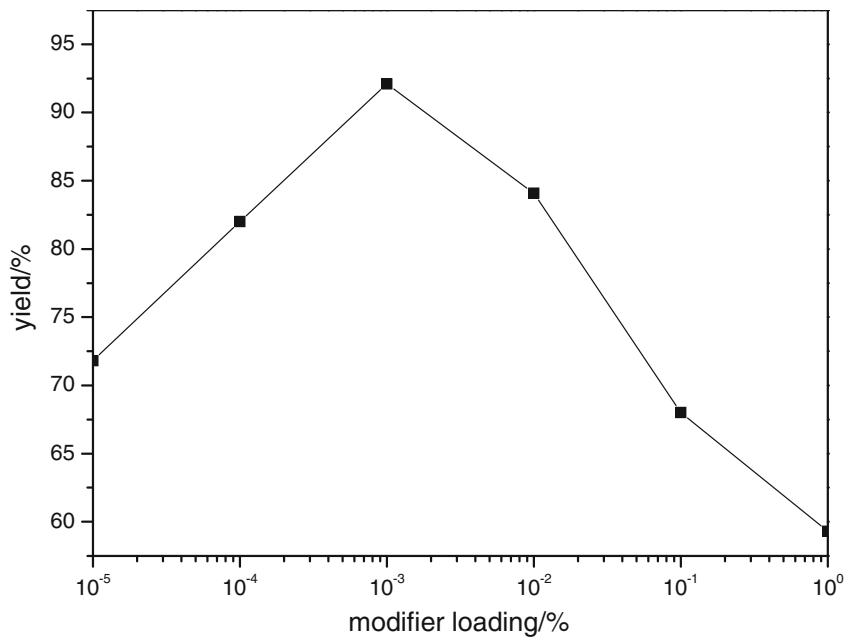

Figure 8. Effect of modifier loading on Aldol condensation of cyclohexanone and benzaldehyde (catalyst amount $=$ $20 \mathrm{wt} \%$, reaction time $=12 \mathrm{~h}$, reaction temperature $=65^{\circ} \mathrm{C}$ ).

\subsection{Catalytic performance over different benzaldehydes}

The Aldol condensations of cyclohexanone with different benzaldehydes over commercial $\mathrm{CaO}$ and $0.1 \%$ benzyl bromide modified $\mathrm{CaO}$ were investigated at the optimum reaction condition (catalyst amount $=20 \mathrm{wt} \%$, reaction time $=3 \mathrm{~h}$, reaction temperature $=65^{\circ} \mathrm{C}$ ) and shown in table 1 . From this table, it was found that the modified $\mathrm{CaO}$ can catalyse the reaction in a very short time to give high yields, while the yields over $\mathrm{CaO}$ are much lower in $3 \mathrm{~h}$, in other word, the modified $\mathrm{CaO}$ accelerates this condensation effectively. Further more, we can find the substitutes of benzaldehyde also affect the yield. The benzaldehyde with strong electronwithdrawing groups $-\mathrm{NO}_{2}$, (entries 1 and 2) give higher yield, but for entry 3 the low yield may be due to the poor selectivity to 2-benzylidenecyclohexanone. Relatively weak electron-withdrawing groups lead to moderated yields and electron-donor groups give lower conversion. Besides, the ortho substituted groups lower the yield for the stereochemistry (entries 3, 4, 6, 7, 11).

\subsection{Catalytic mechanism}

The possible reaction mechanism of Aldol condensation between cyclohexanone (A) and benzaldehyde (B) over $\mathrm{CaO}$ was illustrated in scheme 3 . In this case, the $\mathrm{CaO}$ captures a proton and promotes the rearrangement reaction of cyclohexanone to form $\mathbf{C}$, which is an active intermediate of the Aldol condensation. Through a classical nucleophile attacking of $\mathbf{C}$ to benzaldehyde, intermediate $\mathbf{D}$ is formed. Then, the $\mathrm{Ca}^{2+}$ accept an $\mathrm{O}^{-}$from 
Table 1. Aldol condensations of cyclohexanone with different benzaldehydes.

\begin{tabular}{|c|c|c|c|}
\hline \multirow[b]{2}{*}{ Entry } & \multirow[b]{2}{*}{ Benzaldehydes } & \multicolumn{2}{|c|}{ Yield $1 \%$} \\
\hline & & $\mathrm{CaO}$ & Modified $\mathrm{CaO}$ \\
\hline 1 & & 86.4 & 95.8 \\
\hline 2 & & 85.5 & 98.5 \\
\hline 3 & & 80.2 & 95.0 \\
\hline 4 & & 81.9 & 92.0 \\
\hline 5 & & 81.4 & 98.6 \\
\hline 6 & & 86.4 & 90.6 \\
\hline 7 & & 58.2 & 83.4 \\
\hline 8 & & 81.1 & 98.8 \\
\hline 9 & & 83.5 & 93.3 \\
\hline 10 & & 83.8 & 91.9 \\
\hline
\end{tabular}


Table 1. (continued).

Entry Yield $1 \%$ Modified CaO

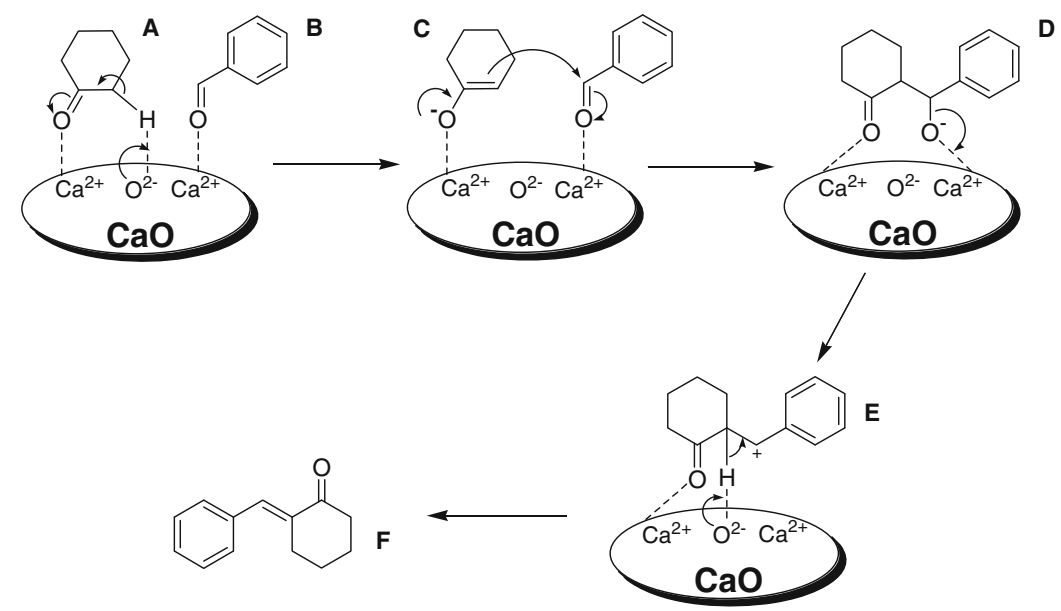

Scheme 3. The possible reaction mechanism of Aldol condensation between cyclohexanone and benzaldehyde over $\mathrm{CaO}$.

$\mathbf{D}$ to form a carbocation $\mathbf{E}$, and the deprotonation of $\mathbf{E}$ results in the formation of product $\mathbf{F}$ at last.

\section{Conclusions}

In this work, an efficient catalyst for the Aldol condensation of cyclohexanone and benzaldehyde using commercial $\mathrm{CaO}$ and modified $\mathrm{CaO}$ as catalysts are shown. It showed that the commercial $\mathrm{CaO}$ is an efficient catalyst for this reaction, and the catalytic activity over modified $\mathrm{CaO}$ enhances greatly and shortens the reaction time from $12 \mathrm{~h}$ to $3 \mathrm{~h}$ with an yield of $90 \%$ under the same condition. The modified $\mathrm{CaO}$ shown good stability in air. It can be attributed to the benzyl groups on $\mathrm{CaO}$ surface, which defend the catalyst from water and improve the adsorption of reactance to catalyst surface. The aldhydes with electron-donor group give good yield. The characterization by FT-IR and TG shows that the modifier bonds to surface of $\mathrm{CaO}$ chemically and the slight hydration of $\mathrm{CaO}$ during modifying process.

\section{Acknowledgements}

This work was financially supported through grants from Scientific Research Program Funded by Natural 
Science Research Plan Projects of Shaanxi Science and Technology Department (No. 2011JQ2014) and PetroChina Innovation Foundation.

\section{References}

1. Roelofs J C A A, Lensveld D J, Dillen van A J and Jong de K P 2001 J. Catal. 203184

2. Cota I, Chimentao R, Sueiras J and Medina F 2008 Catal. Commun. 92090

3. Zhong L, Gao Q, Gao J B and Li C 2007 J. Catal. 250 360

4. Xie Y W, Sharma K K, Anan A, Wang G, Biradar A V and Asefa T 2009 J. Catal. 265131

5. Podrebarac G G, Ng F T T and Rempel G L 1997 Chem. Eng. Sci. 522991

6. Serra-Holm V, Salmi T, Multamäki J, Reinik J, MäkiArvela P, Sjöholm R and Lindfors L P 2000 Appl. Catal. A: General 198207
7. Raju V, Radhakrishnan R, Jaenicke S and Chuah G K 2011 Catal. Today 164139

8. Clacens J M, Genuit D, Delmotte L, Garcia-Ruiz A, Bergeret G, Montiel R, Lopez J and Figueras F 2004 J. Catal. 221483

9. Liu H H, Xu W J, Liu X H, Guo Y, Guo Y L, Lu G Z and Wang Y Q 2010 Kinetics Catal. 5175

10. Tichit D, Lutic D, Coq B, Durand R and Teissier R 2003 J. Catal. 219167

11. Ji W J, Chen Y and Kung H H 1997 Appl. Catal. A: General 16193

12. Díez V K, Apesteguía C R and Di Cosimo J I 2006 J. Catal. 240235

13. Hattori H 1995 Chem. Rev. 95537

14. Ebitani K, Motokura K, Mori K, Mizugaki T and Kaneda K 2006 J. Org. Chem. 715440

15. Wang Y B, Yang D, Zheng X H, Jiang Z Y and Li J 2008 J. Power Sources 183454

16. Christopher W J, Michael T, Tatsuya O and Mark E D 2001 Micropor. Mesopor. Mater. 4221

17. Lopez J, Sanchez Valente J, Clacens J M and Figueras F 2002 J. Catal. 20830 